\title{
Th17 response in patients with cervical cancer (Review)
}

\author{
JAYRA JULIANA PAIVA ALVES ${ }^{1}$, THALES ALLYRIO ARAÚJO DE MEDEIROS FERNANDES ${ }^{2}$, \\ JOSÉLIO MARIA GALVÃO DE ARAÚJO ${ }^{1}$, RICARDO NEY OLIVEIRA COBUCCI ${ }^{3}$, \\ DANIEL CARLOS FERREIRA LANZA ${ }^{4}$, FABIANA LIMA BEZERRA ${ }^{1}$, \\ VÂNIA SOUSA ANDRADE ${ }^{1}$ and JOSÉ VERÍSSIMO FERNANDES ${ }^{1}$ \\ ${ }^{1}$ Department of Microbiology and Parasitology, Federal University of Rio Grande do Norte, Natal, RN 59072-970; \\ ${ }^{2}$ Department of Biomedical Sciences, University of Rio Grande do Norte State, Mossoró, RN 59607-360; \\ ${ }^{3}$ Department of Gynecology and Obstetrics, Potiguar University, Natal, RN 59056-00; \\ ${ }^{4}$ Department of Biochemisty, Federal University of Rio Grande do Norte, Natal, RN 59072-970, Brazil
}

Received January 8, 2018; Accepted August 7, 2018

DOI: $10.3892 / \mathrm{ol} .2018 .9481$

\begin{abstract}
Persistent infection by high-risk human papillomavirus (HR-HPV) is the main risk factor for uterine cervical cancer (UCC). However, viral infection alone is not sufficient for the development and progression of premalignant cervical lesions for cancer. In previous years it has been suggested that the adaptive immune response triggered by the differentiation of naïve helper T cells in Th17 cells may serve an important role in disease development. It has been hypothesized that Th17 cells may be involved in the promotion of UCC, as high levels of interleukin 17 (IL17) expression have been detected in the mucosa of the uterine cervix of patients affected by the disease. However, the role of Th17 cells in the tumor development and progression remains unclear. It is believed that the immune response of the Th17 type during persistent infection of the genital tract with HR-HPV triggers chronic inflammation with a long duration with the production of IL17 and other pro-inflammatory cytokines, creating a favorable environment for tumor development. These cytokines are produced by immune system cells in addition to tumor cells and appear to function by modulating the host immune system, resulting in an immunosuppressive response as opposed to inducing an effective protective immune response, thus contributing to the growth and progression of the tumor. In the present review, the latest advances are presented about the function of Th17 cells and the cytokines produced by them in the development and progression of UCC.
\end{abstract}

Correspondence to: Professor Thales Allyrio Araújo de Medeiros Fernandes, Department of Biomedical Sciences, University of Rio Grande do Norte State, Rua Miguel Antônio da Silva Neto, S/N, Mossoró, RN 59607-360, Brazil

E-mail: thalesallyrio@yahoo.com.br

Key words: Th17 cells, uterine cervical cancer, carcinogenesis, immune system

\section{Contents}

1. Introduction

2. Differentiation of $T$ helper cells

3. Biology and functions of $\mathrm{T}$ helper 17 cells

4. Role of Th17 cells in UCC

5. Cells producing IL-17

6. Cells expressing receptors for the IL-17 family

7. Role of IL-17 in UCC

8. Conclusion

\section{Introduction}

Uterine cervical cancer (UCC) is a tumor of epithelial cells located in the cervix that affects women around the world (1). An estimate of the overall disease incidence for the year 2012 (2) revealed the notification of 528 thousand new cases, with a record of 266 thousand deaths worldwide, making this malignant neoplasm the fourth most common cancer among women, representing the fourth cause of cancer death among women worldwide (3). UCC is considered the second most common cancer and the third leading cause of death by cancer among women in less developed countries, with higher incidence and mortality rates in sub-Saharan Africa, Melanesia, Latin America, and the Caribbean (2).

The natural history of the UCC clearly shows the close relationship between the disease and persistent infection with genotypes of high-risk human papillomavirus (HR-HPV), since the viral genome sequences are detected in tumor cells of virtually all cases of the disease (4). Despite its high prevalence due to its infectious nature, UCC stands out among the malignant neoplasms with the greatest potential of prevention and cure (5). The wide variation in incidence and mortality rates of UCC in different geographic regions reflects the economic, social, and cultural differences (6), as well as the availability of screening tests, which allow early detection and removal of precancerous lesions $(7,8)$.

In most cases the infection is transient and asymptomatic without the presence of injury, or has only low-grade lesions 
that regress to spontaneous healing in a period of up to two years (9). However, in a proportion of women infected with oncogenic genotypes of the virus, the symptoms disappear but the virus is not eliminated; rather, it remains in the form of persistent infection (10). A number of women with persistent infection develop cervical intraepithelial neoplasia (CIN), which can progress to UCC. The progression to cancer occurs when the virus integrates the chromosomes of the host cell and depends on other factors such as epigenetic events triggered by physical, chemical, and environmental factors, as well as host characteristics including nutritional status, genetic background, and immune status $(11,12)$.

The absence of a cure for HPV infection seems to be related to escape mechanisms used by HPV to evade the host immune response. HR-HPV avoids immunological recognition by inactivating the cells of the innate immune response, downregulating the type I interferon production and inducing peripheral tolerance of cytotoxic T lymphocytes (CTL) $(13,14)$. One possible explanation for this is the fact that the infection is restricted to the epithelium, with no occurrence of viremia with the spread of the virus, nor lyses, degeneration or necrosis of cells, or damaging signs to alert the immune system (15). Thus, there is no activation of an inflammatory response with the necessary cytokine production for recognition of the virus as a pathogenic agent. This hinders the proper activation of the local immune response, which may favor an induction of immune tolerance to the virus and which therefore becomes undetectable after long periods of time, promoting the immune evasion of the infected cells (16).

HPV infection induces weak immunity due to the action of viral proteins that activate multiple mechanisms to prevent initiating a robust immune response. The most notable among these mechanisms are the depletion of Langerhans cells (LCs) mediated by viral protein E6; the downregulating of MHC molecules of class I by E5, avoiding the attack of CTL; and the blocking of the signaling pathway of type I interferon by E7 (17). Furthermore, the downregulating of IFN expression by viral proteins E6 and E7 results in an absence of co-stimulatory signals by inflammatory cytokines, including IFN for recognizing antigens that can induce immunological tolerance rather than an effective immune response (18).

Thus, the curing of HPV-induced lesions is dependent on a cell-mediated immune response, requiring interactions between CD4+ and CD8+ T lymphocytes. LCs are probably responsible for triggering an anti-HPV immune response, but the function of these cells is interrupted by HPV at different levels (19). The epithelium of the uterine cervix is a very poor microenvironment in immunological mediators, and therefore appears to be immunologically hyporesponsive to HPV since this virus induces a local immune deficiency by the depletion of CD4+ and LCs, as well as the downregulating of the cytokine production (20). Additionally, the vaginal epithelium has a dendritic cell (DC) subset that does not express Langerin (Lang-DC), exerting the downregulation of CTL in the cervical mucosa by a mechanism that may involve interleukin (IL)-17, and IL-10 to a lesser degree (21).

When the antigen presentation occurs in the absence of cytokines that favor the response of the Th1 type, differentiation into other types of response can occur, including Th2 or Th17. This results in a less-efficient T-cell response, promoting viral persistence and increasing the risk of cervical lesions of different degrees, as well as the progression to cancer (22). Furthermore, there may be unbalanced activation of Th17 and regulatory T cells (Treg), which can compromise the efficiency of the immune response, reducing their suppressive action on the tumor, and also possibly favoring tumor development and progression (23-25).

Persistent HPV infection may affect cell differentiation of the adaptive immune response including CD4+/CD8+ T cells and Treg cells, resulting in immune tolerance of the host to the infected cells. Thus, a compromised cellular immune response, an abnormal imbalance between type $1 \mathrm{~T}$ helper (Th1) and Th2 cells, infiltration of Treg cells, and the downregulation of activating and maturing DCs may contribute to the progression of HPV-associated premalignant lesions for UCC (16). It has been reported that high expression levels of IL-17, which is the main cytokine of the Th17 response, are associated with poor UCC prognosis, but the role of this kind of response in tumor progression is still ambiguous (26). This review was performed to analyze recent advances on the immunological and molecular mechanisms involved in the immune response of the Th17 type, and their role in the progression of HPV-associated lesions for cancer.

The literature search was conducted using the electronic databases of PubMed (National Institutes of Health, Bethesda, MD, USA; www.ncbi.nlm.nih.gov/pubmed), Scopus (Elsevier, Amsterdam, Netherlands; www.scopus.com/scopus/home. url), and Web of Knowledge (Thomson Reuters, New York, NY, USA; www.webofknowledge.com), using the following keywords: Th17, Th17 cells, IL-17, HPV Infection, Cervical Cancer, HPV infection, HPV-associated cervical lesions. The databases retrieved thousands of articles and those thought to be most relevant were selected, which included recent studies published in impact journals conducted by groups with recognized expertise in the areas of immunity and cancer, and mainly cervical cancer.

\section{Differentiation of $\mathbf{T}$ helper cells}

After the first contact with its specific antigen through antigen-presenting cells (APC), the specific clone of the naïve TCD4+ cell acquires the potential to differentiate into effector $\mathrm{T}$ cells with a variety of different phenotypes of each other $(27,28)$. These different types of cells, called T-helper cells, acquire the ability to produce and secrete cytokines through a differentiation process triggered in response to multiple signals of the environment, including cytokines (29). These cells are crucial for mounting an adaptive immune response that protects the host against both the infection caused by pathogens and the development of tumors (30). However, the responses induced by these cell types may also trigger immunopathological mechanisms that result in tissue damage, similar to those observed in the infections caused by intracellular pathogens such as viruses, autoimmune disorders, and allergies (31).

Only two types of T-helper cells were initially identified. One was the Th1 cell, described by Mosmann et al (32), which develops in response to IL-12, signaling, producing and especially secreting IFN- $\gamma$ and regulating cell-mediated protective immunity against intracellular pathogens (33). The other type 
identified was the Th2 cell, described by Murphy et al (34), which develops in response to IL-4, signaling, producing and secreting IL-5 and IL-13 and regulating protective immunity against extracellular pathogens (33). This dichotomy of Th1/Th2 prevailed in the field of immune regulation until recently, when new phenotypes of T-helper cells were identified $(27,28)$.

The enormous complexity of the cell-mediated immune response revealed by experimental studies had already indicated that this model (based on only two subtypes of Th cross-regulatory cells) would be insufficient to explain the various aspects of initiation, regulation, and fine-tuning of several types of immune responses triggered by the host in response to the environmental stimuli (28). Later, a new type of Th cell was discovered, called regulatory $\mathrm{T}$ or Treg that expresses Foxp3, a transcription factor, and represents a negative regulation mechanism of immune-mediated inflammation to prevent self-destructive immune responses, including autoimmune and auto-inflammatory disorders, allergies, and cancer $(35,36)$.

In the last 10 years, three additional Th cell subtypes were identified and named according to the type of cytokine secreted by each of them (28). One of them was Th17, a subtype of Th that produces and secretes high levels of IL-17 (33), in addition to other inflammatory cytokines such as IL-21 and IL-22, and are involved in tumor progression by promoting angiogenesis and immunosuppressive activities. However, Th17 cells may also act by mediating antitumor immune responses by promoting recruitment of immune cells to the tumor site, activating effector CD8+ T cells against the tumors, or even reverting to the Th1 phenotype by producing IFN- $\gamma$ which promotes further activation of CD8+ T cells. Thus, these cells have an ambiguous function in relation to the tumors (37). The others subtypes are Th9 cells, which produces and secretes IL-9 (38), and Th22, which produces and secretes IL-22 (39). This shows that adaptive cell-mediated immune response involves a complex network of interactions between cells with different phenotypes through a suite of mediators, mainly cytokines.

The differentiation of naïve CD4+ T helper cells in the Th17 cell is stimulated by the combined action of TGF- $\beta$ and of pro-inflammatory cytokines such as IL-1 $\beta$, IL-6, IL-21, and IL-23, which play a central role in generation of these cells (40). The TGF- $\beta$ signaling appears to play a critical role in the differentiation of Th17, since TGF- $\beta$ inhibition substantially reduces the generation of these cells. It has been discussed whether TGF- $\beta$ is in fact necessary for generating Th17, as it has been shown that murine $\mathrm{T}$ cells can be differentiated in Th17 using IL-1 $\beta$, IL-6, and IL-23 in the absence of exogenous TGF- $\beta$. However, treatment with anti-TGF- $\beta$ antibody inhibited this differentiation, suggesting the involvement of endogenous TGF- $\beta$ in the differentiation process (41).

What differentiates the lineages of TCD4 cell from each other is the signature transcription factor that each them express. Thus, Tregs are marked by the expression of FOXP3 induced during its maturation in the thymus, or in the periphery induced by TGF- $\beta$ and retinoic acid. On the other hand, the signature transcription factor for Th17 cells, retinoid-related orphan receptor $\gamma \mathrm{t}(\mathrm{ROR} \gamma \mathrm{t})$, is also induced by TGF- $\beta$, thus linking the differentiation of Treg and Th17 lineages. Therefore, in the absence of a second signal emitted by a proinflammatory cytokine, FOXP3 can inhibit ROR $\gamma$ t function, and leads to differentiation of TCD4 in Treg. However, when that same cell receives the second signal from a proinflammatory cytokine, such as IL-6, the FOXP3 function is inhibited and the cell differentiates in Th17. Therefore, the balance between the FOXP 3 and ROR $\gamma$ t function is that it determines the fate of CD4+ T cells and the type of immune response that will be generated (42).

The role of GAT3 in Th17 cell differentiation was analyzed in an experimental murine model of arthritis induced with methylated bovine serum albumin, in both wild type and in CD2 T-cell-specific GATA-3 (CD2-GATA-3)-transgenic mice. It was found that wild-type mice developed severe joint inflammation with massive inflammatory cell infiltration and bone erosion, while the CD2-GATA-3 transgenic mice only presented mild joint inflammation, accompanied by systemic and local reductions in the numbers of IL-17+ IFN- $\gamma$ - and IL-17+ IFN- $\gamma+$, but not of IL-17-IFN- $\gamma$ cells and CD4+ T cells, by inducing cytokine expression with Th2 profile. In addition, overexpression of GATA-3 resulted in reduced expression of the gene encoding ROR $\gamma$ t, the signature transcription factor of Th17 cells. These results indicate that GATA-3 protects against joint inflammation and bone erosion by inhibiting the differentiation of Th17, but not Th1 cells in experimental arthritis in mice (43).

Ovarian tumor cells, tumor-derived fibroblasts and antigen presenting cells (APCs) have also been shown to secrete cytokines such as IL-1 $\beta$, IL- 6 , TNF- $\alpha$ and TGF- $\beta$, which create a favorable environment for differentiation and expansion of IL-17 producing cells. It further shows that IL-1 $\beta$ is required for the differentiation and expansion of human Th17 cells, while IL-6 and IL-23 may also play a role in the expansion of Th17 memory cells, although IL-23 levels are low or undetectable in ovarian cancer (44).

In humans, Th17 differentiation is induced in the presence of IL-1 $\beta$, IL- 6 and TGF- $\beta$ cytokines, while the IL-23 cytokine is responsible for the maintenance of Th17 cell survival. Effector Th17 cells express various cytokines and cell surface markers, including IL-17A, IL-17F, IL-22, IL-26, CCR6 and TNF- $\alpha$. It has been shown that the RORC2 transcription factor in human cells plays a critical role in Th17 cell differentiation. The differentiation process of Th17 cells is controlled by many transcription factors, including ROR $\gamma \mathrm{t}$, interferon regulatory factor 4 (IRF4), runt-related transcription factor 1 (RUNX1), basic leucine zipper ATF-like transcription factor (BATF) and signal transducer and activator of transcription 3 (STAT3) (45).

It was found that TGF- $\beta$ induces differentiation of Th17 cells by reversing the ROR $\gamma$ t suppression related to the retinoic acid receptor (RAR), mediated by SKI-SMAD4. This has been proven since SMAD4-deficient T cells differentiate into Th17 cells in the absence of TGF $\beta$ signaling in a ROR $\gamma \mathrm{t}$-dependent manner, unlike in wild-type $\mathrm{T}$ cells. Expression of ectopic SMAD4 suppresses ROR $\gamma \mathrm{t}$ expression and prevents differentiation of Th17 cells from SMAD4-deficient T cells. However, TGF- $\beta$ neutralizes SMAD4-mediated suppression, since in order to suppress the ROR $\gamma$ t function, and SMAD4 needs to interact with SKI, which is a transcription repressor that is degraded after the cell is stimulated by TGF $\beta$ (46). 
It has been shown that phosphatase and tensin homologue (PTEN) play an important role in the differentiation of Th17 cells, promoting the blockade of IL-2 expression. In an in vitro study it was shown that Th17-specific Pten deletion $\left(\right.$ Pten $\left.^{\text {flffl}} I l 17 a^{\text {cre }}\right)$ impairs the differentiation of Th17 cells and improves the symptoms of experimental autoimmune encephalomyelitis, a model of Th17 mediated autoimmune disease. The Pten-deficiency upregulates IL-2 expression and STAT5 phosphorylation, but downregulates STAT3 phosphorylation, which results in inhibition of Th17 cell differentiation (47). In another study it was shown that reduced expression of RFX1 transcription factor in CD4+ T cells from patients with systemic lupus erythematosus determine overexpression of IL-17A, which increased the histone $\mathrm{H} 3$ acetylation and decreased DNA and H3K9 tri-methylation. This indicates that the differentiation of CD4 + T cells into Th17 cells may also be influenced by epigenetic modifications of the DNA. As the functions of RFX1 downstream of STAT3 and p-Stat3 can inhibit RFX1 expression, a non-canonical pathway that regulates differentiation of Th17 cells exists (48).

In humans the differentiation of naïve CD4+ T helper cells in the Th17 cell occurs in the presence of IL-1 $\beta$ and IL-6, depending on the transcription factor STAT3. The cytokine IL-23 produced by dendritic cell activity increases and stabilizes the cells with phenotype Th17 and helps these cells acquire effector functions. The Th17 cells secrete IL-17, IL-21, and IL-22, which play a significant role in the immune response against pathogens, but which also contribute to the pathogenesis of inflammatory and autoimmune disease. Furthermore, a Th17 cell subpopulation has been found in many types of cancers, but it is not yet clear whether the Th17 cell promotes or inhibits tumor progression (49). A representative scheme is proposed in Fig. 1 to summarize the mechanisms and cytokines involved in the differentiation process of naïve CD4+ T cells (Th0) in Th17 cells, and the possible role of these cells in tumor progression.

\section{Biology and functions of $\mathrm{T}$ helper 17 cells}

The Th17 cell belongs to a subset of T-helper cells, characterized as producers of tumor necrosis factor- $\alpha(\mathrm{TNF} \alpha)$ and IL-17, which indeed represent a family of cytokines composed of IL-17A, IL-17B, IL-17C, IL-17D, IL-17E, and IL-17F, in addition to producing IL-6, IL-21, IL-22, and IL-23 (50). Cells with this phenotype were identified as a new lineage of T-helper cells with a key role in host defense against extracellular infectious agents by mediating effector mechanisms through its cytokines, but it is also associated with chronic inflammatory disease, autoimmune disorders, and cancer (51).

An extensive list of diseases has been associated with the major product of the Th17 cell, the cytokine IL-17, but the definitive demonstration of its contribution to the pathogenesis of these diseases is still little known. It is believed that IL-17 has a regulatory function of the host defense and of chronic inflammation, but its action could result in damage to tissues and autoimmunity. Thus, IL-17 establishes a link between innate and adaptive immunity with disease, and may have physiological or pathological effects on the immune system. Evidence supports the notion that the production of unregulated IL-17 and IL-21 by Th17 cells may contribute to the pathogenesis of autoimmune diseases (50).

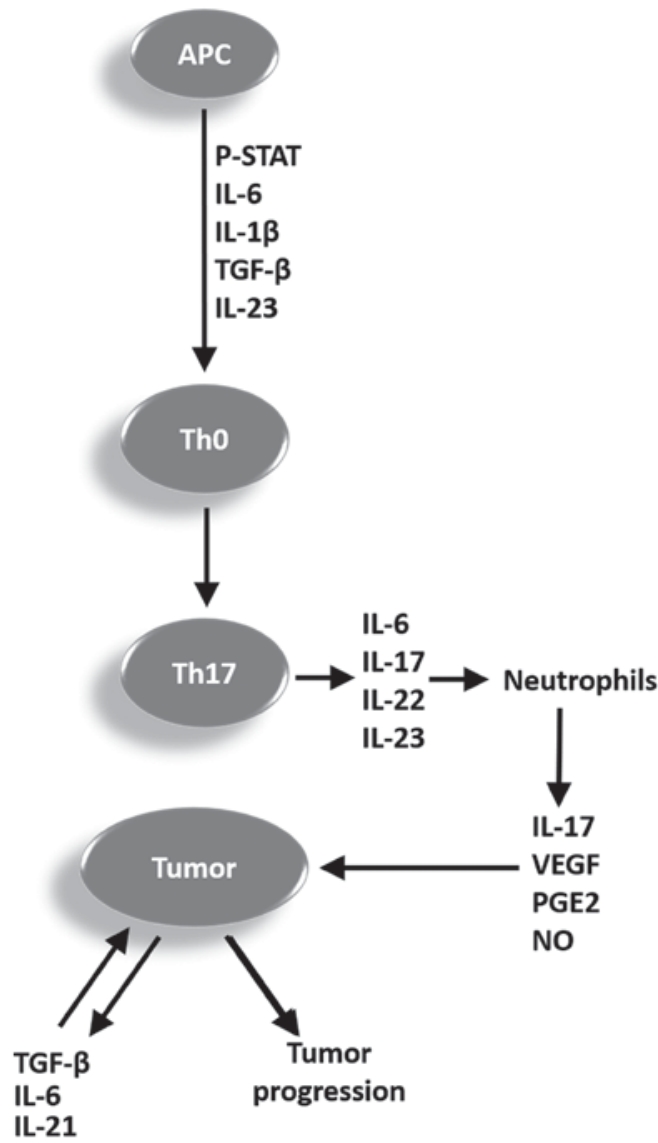

Figure 1. Representative scheme summarizing the mechanisms and cytokines involved in the differentiation process of Th0 in Th17 cells, and the potential function of these cells in tumor progression. APC, antigen-presenting cell; p-STAT, phosphorylated signal transducer and activator of transcription; IL, interleukin; TGF- $\beta$, tumor growth factor $\beta$; Th, Thelper cell; VEGF, vascular endothelial growth factor; PGE2, prostaglandin E2; NO, nitric oxide; Th0, $\mathrm{CD}^{+} \mathrm{T}$ cells.

It has been shown in co-cultures that LPS was the most potent stimulator for activating loaded macrophages of antigen to conduct the polarization for Th17 response in both CD4+ cells and CD45RO+ memory cells, while IFN- $\gamma /$ LPS preferably activates macrophages to the Th1 phenotype. Antigen-loaded dendritic cells were more efficient than macrophages in conducting the response of the Th1 type. However, the ability of Th17 to polarize these two types of antigen-presenting cells was equivalent and showed to be strongly dependent on IL-1 $\beta$. This clearly shows that human macrophages activated in different ways also have different ways to present antigens, and this affects adaptive immunity in vivo, particularly in the conducting polarization to Th17 in inflamed tissues (52).

Because of the accumulation of Th17 cells in many types of tumors compared to healthy tissue, the Th17 cells were associated with both good and bad prognosis regarding tumors, although the intensity is different from one tumor type to another. The high plasticity of Th17 cells compared to other cells that exhibit either protective or pathogenic functions can contribute to versatile functions of the Th17 cell in the tumor context. Thus, on one hand Th17 cells can promote tumor growth by angiogenesis induction mediated by IL-17 and exert an immunosuppressive function; on the other hand, Th17 cells can lead to an antitumor immune 


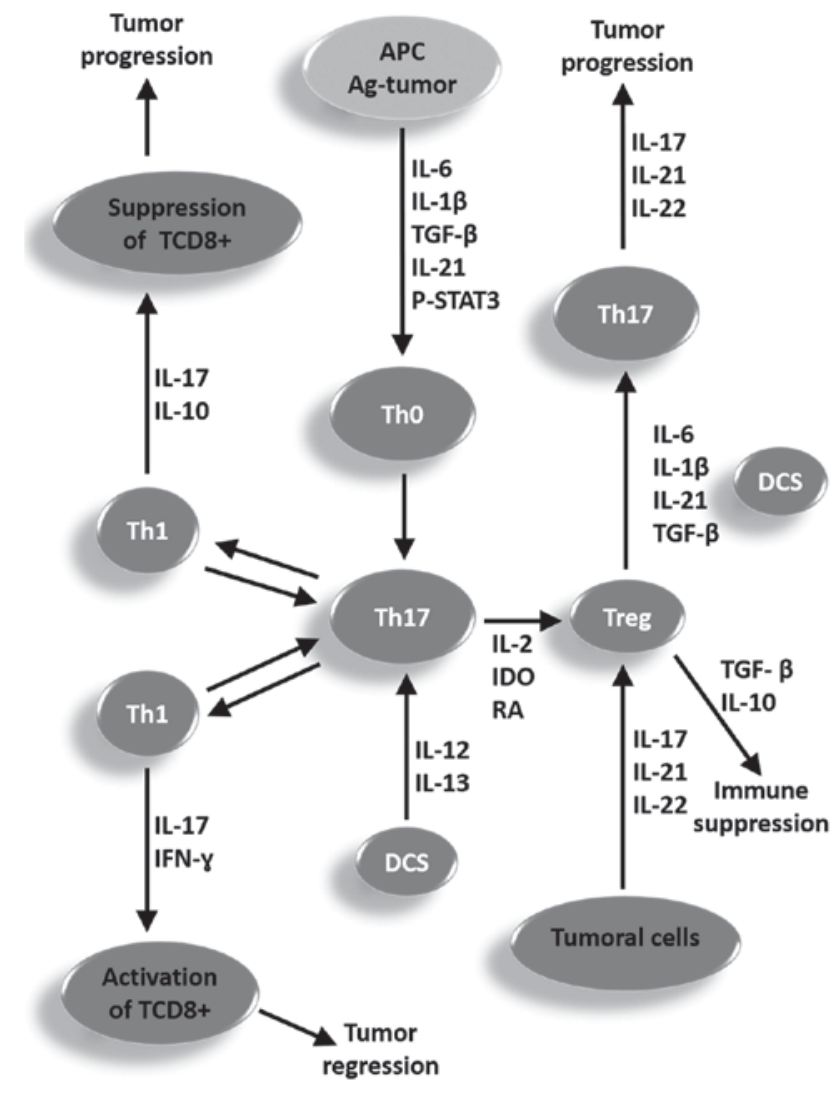

Figure 2. Representative scheme proposed for summarizing the function of different cell types, mechanisms and cytokines involved in the plasticity process and reciprocity in the conversion of Th1, Th17 and Treg cells for a better understanding of the ambiguous functions of the Th17 cells in the clinical course of a tumor, which may contribute to the regression or progression of a tumor. APC, antigen-presenting cell; p-STAT, phosphorylated signal transducer and activator of transcription; IL, interleukin; TGF- $\beta$, tumor growth factor $\beta$; Th, Thelper cell; IDO, indoleamine 2,3-dioxygenase; DCS, dendritic cells; Treg, T regulatory cells; IFN- $\gamma$, type II interferon.

response through recruitment of immune cells to the microenvironment of the tumor and activate CD8+ T effector cells against the tumor, in addition to being able to act directly through conversion to the Th1 phenotype producing IFN $-\gamma$, which in turn activates more CD8+ cells against the tumor (53).

Despite some advances in knowledge about the role of Th17 cells in tumor biology, many aspects remain unclear. The greatest challenge faced by researchers is the plasticity of these cells within the tumor microenvironment, where they can be converted into other subsets of Th cells, including Th1 and Treg cells. Thus, it is necessary to identify the molecular mechanisms and factors that act in the tumor microenvironment which are responsible for plasticity and reciprocity in the conversion of Th1, Th17 and Treg (53). Evidence suggests that there is a dynamic interaction and mutual conversion between Treg and Th17 cells in the tumor microenvironment in which the number of these cells seems to be mutually linked to tumor progression $(54,55)$. Furthermore, two different subpopulations of Th17 cells have been found infiltrated in the tumors, including Th17 cells producing IL-17 and IFN- $\gamma$, and Th17 cells producing IL-17 and IL-10. It is possible that the generation of these two types of Th17 cells is due to variations in the cellular circumstances and tumor stage (53).
It has been shown that receptors for IL-17 and IL-22 are widely expressed in various epithelial tissues. Therefore, the cytokines secreted by Th17 cells mediate a critical crosstalk between the immune system and tissues, and play an essential role in immunity (56). It has been shown that Th17 cells have a high degree of functional plasticity, being endowed with the ability to be converted into Th1 cells producing IL-17 and IFN- $\gamma$, or IL-17 and IL-10, or into Treg cells $(57,58)$. Because of its high plasticity, Th17 cells exhibit the ability to shift rapidly to the Th1 phenotype in the inflammatory sites. Thus, in these places there is usually a dichotomous blend of classic Th1 cells and non-classical Th1 cells derived from Th17 expressing CD161. Initial studies in this field show evidence suggesting that the non-classical Th17-derived Th1 cell appears to play a more important role than the classical Th1 in the maintenance of chronic inflammation and various autoimmune diseases (59).

Studies conducted in patients with inflammatory disease of the intestinal tract showed that cytokine IL-23 has an important role as an inhibitor in the generation of Treg cells (60). Furthermore, signaling by IL-23 together with IL-12 both produced by monocyte-derived dendritic cells (61) promotes IFN- $\gamma$ secretion from Th17 cells, thus determining the plasticity of Th17/Th1 (62). A similar situation could occur in relation to tumors. This plasticity of Th17 cells can lead to the conversion of these cells in two subsets of non-classical Th1 cells, expressing CD161. One of them produces and secretes IL-17 and IFN- $\gamma$, promoting the activation of CD8+ T lymphocytes with cytotoxic activity, contributing to tumor regression. The other subset of non-classical Th1 cells produces IL-17 and IL-10, and unlike the first this subset suppresses the activity of CD8+ T cells and promotes chronic inflammation, which may favor tumor progression (57).

The contribution of Th17 cells for immunity against tumors in humans remains largely unknown. Since its discovery, Th17 cells have been extensively studied in tumors in both animal and human models. The obtained results suggest the importance of Th17 cells in immunity against tumors, but the functional role of these cells in tumors remains controversial. The knowledge obtained from studies in murine tumor models suggests that Th17 cells can exert pro-or antitumor action, depending on the tumor model used, the source of IL-17 and Th17 cells, as well as the specific cytokine and conditions within the tumor (57).

In the tumor microenvironment, cells with the Th17 phenotype may be converted into Treg cells when activated by tumor antigens in the presence of factors such as IL-2, retinoic acid (RA), and indoleamine 2,3-dioxygenase (IDO) produced by tumor cells, thereby producing TGF- $\beta$, IL- 6 , and IL-10. In turn, the Treg cells being stimulated by cytokines such as IL-6, IL-21, and TGF- $\beta$ produced by tumor cells can be converted into Th17 cells, producers of IL-17, IL-21, and IL-22. The role of Th17 in any study is to promote or inhibit tumor growth. Therefore, extensive research on Th17 cells in patients with different tumor types and in different stages is critical for advancing knowledge in this area (57).

In Fig. 2 a representative scheme is proposed for summarizing the role of different cell types, mechanisms, and cytokines involved in the plasticity process and reciprocity in conversion of Th1, Th17, and Treg cells for a better 
understanding of ambiguous functions of the Th17 cells in the clinical course of tumors, which can contribute to the regression or progression of tumors.

The subcutaneous injection of lung carcinoma cells in mice followed by intraperitoneal injection of IL-17 or PBS showed that the animals inoculated with IL-17 presented significantly greater tumors with higher levels of metastasis, the largest infiltration of CCR2+ macrophages and the largest number of vascular endothelial cells expressing CD34 when compared to animals injected with PBS. Furthermore, higher levels of mRNA expression of the vascular endothelial growth factor (VEGF), matrix metalloproteinase (MMP)2, MMP9, and TNF- $\alpha$, and lower expression levels of the migration inhibitory factor and thrombospondin-1 were observed in animals inoculated with IL-17. The authors concluded that IL-17 can promote tumor growth by increasing angiogenesis, metastasis, and the number of CCR2+ macrophages (63). On the other hand, mice with pre-malignant oral lesions induced by carcinogenic agents presented a differentiation tendency of the CD4+ helper cells to the phenotypes Th1 and Th17, as well as drainage of these spleen cells to the lymph nodes with a shift to the Treg phenotype, followed by cancer progression. The treatment of the animals with premalignant oral lesions with an inhibitor of the TGF- $\beta$ receptor plus IL- 23 not only maintained the Th17 phenotype, but also increased the number of these cells in the spleen and regional lymph nodes, and slowed the progression of pre-malignant lesions to cancer (64).

\section{Role of Th17 cells in UCC}

Evidence of Th17 cells in playing some role in the development of cervical cancer is the fact that accumulation of these infiltrates in the tumor tissue has been associated with a greater chance of tumor recurrence. Also, it was found that Th17 cells infiltrated into the tumor had an activated phenotype with increased expression of CCR6, the chemokine receptor CCL20. Correspondingly, the level of CCL20 in tumor tissues was significantly higher when compared to normal and non-tumor tissues. In addition, levels of this chemokine were positively associated with the amount of Th17 cells (65).

The local immune responses in women with CIN or UCC were evaluated in two separate studies involving Chinese women. In the first it was observed that TCD4+cells expressing Foxp3 accumulated around the tumor in a significantly higher proportion than found around the CIN. Also, the patients with UCC who had metastasis of the lymph nodes showed a greater proportion of $\mathrm{T}$ cells expressing Foxp3 compared with those without metastasis (66). The second study revealed that patients with CIN and UCC had a greater number of Th17 cells compared to healthy women. A significant increase in Treg cells and plasmatic concentrations of cytokines IL-17 and IL-10 was observed in patients with UCC, but not in those who had CIN. The prevalence of Th17 cells in the cancer patients was associated with the clinical stage of disease, the presence of metastasis and vasoinvasion, while the increase in Treg cells was associated with the degree of tumor differentiation. Surprisingly, an important imbalance was found in the Th17/Treg relation, both in patients with UCC as well as in those with CIN. The imbalance in the Th17/Treg ratio was significantly higher in women with cancer that had developed metastasis or vasoinvasion compared with those that had not. These results reinforce the hypothesis that the imbalance of Th17/Treg may be involved in the promotion and progression of UCC (23).

Patients with CIN or UCC have been shown to have a higher proportion of Th17 cells and Foxp3-expressing T cells among lymphocytes infiltrated into the tumor when compared to healthy women with no history of cervical lesions. When comparing the Th17/ $\mathrm{T}$ cell ratio expressing Foxp3 among the infiltrated lymphocytes decreased in the sick women, it was markedly reduced in lymphocytes infiltrated in the tissues of healthy women. The cytokine IL- 6 , TGF- $\beta$ and IL-10 concentrations were significantly higher in UCC patients than those in healthy women. This reinforces the hypothesis that an imbalance of Th17/Foxp3-expressing T cells plays a critical role in UCC, and that Th17 cells can promote initiation and progression of this tumor (67).

A higher proportion of Th17 cells and Foxp3-expressing $\mathrm{T}$ cells were found in patients with UCC compared with the proportion found in healthy women. The ratio of Th17/Foxp3-expressing $\mathrm{T}$ cells among the tumor-infiltrating lymphocytes (TILs) was more markedly decreased when compared to normal cervical tissues. Furthermore, the average concentrations of the cytokines IL- 6 , TGF- $\beta$, and IL-10 were significantly higher in patients with UCC compared with healthy women. Interestingly, the amount of Th17 cells in the tumor environment has been positively correlated with microvessel density. Thus, the imbalance in the ratio of Th17/Foxp3-expressing T cells may play a critical role in both promotion and progression of the UCC, where Th17 cells may contribute to tumor progression by promoting angiogenesis (67).

It has been shown that patients with CIN and UCC have significantly lower IFN- $\gamma$ levels than those in the control group, observing an inverse relationship to the number of Treg cells, thereby suggesting that Treg cells suppress IFN- $\gamma$ production by NK cells and CTL activity. The participation of Th17 cells in the development of the UCC could be through the IL-17 secretion, which in turn induces angiogenesis and promotes tumor growth. The levels of TGF- $\beta$, IL-6, IL-10, IL-17 and IL-23 were significantly higher in patients with CIN and UCC than those in the control group, with a positive correlation between the percentages of Th17 cells and levels of IL-6, IL-23, and IL-17. The Treg percentage of cells was positively correlated with elevated levels of TGF- $\beta$, IL- 6 , and IL- 10 . This suggests that TGF- $\beta$ cytokine, IL-6, IL-17, and IL-23 promote an imbalance in the Th17/Treg relationship, and this alteration may be a possible mechanism by which Th17 cells contribute to the development of UCC (68). Once that Treg cells are highly expressed in UCC, it can be inferred that they play a crucial role in the development and progression of the disease, since Treg cells are correlated with the growth, metastasis, and vasoinvasion in UCC (69). Considering that Th17 cells can be converted into Treg cells due to their high plasticity, this could be a possible mechanism of participation of Th17 cells in the promotion and progression of this tumor type.

Immunopathological analysis of patients with CIN2 or CIN3 HPV-associated lesions and murine skin with epithelial hyperplasia and protein-induced HPV16 E7, used as a chronic injury model induced by HPV, showed a high expression of 
IL-17 and IL-23, a major inducer of IL-17. Using the HPV16 E7 transgenic skin graft animal model, it was demonstrated that IL-17 was able to efficiently inhibit the immune response against the graft. It was also found that IL-17 was predominantly produced by CD4(+) T cells in human CIN2 or CIN3 lesions, and by $\mathrm{CD} 4(+)$ and $\gamma \delta \mathrm{T}$ cells in murine hyperplasic skin lesions. IL-23 and IL-1 $\beta$, but not IL-18, induced the production of IL-17 in E7 transgenic skin, showing that IL-17 induces an immunosuppressive effect in epithelial hyperplasia associated with HPV. This suggests that blocking IL-17 in the persistent viral infections can promote the antiviral immunity and prevent progression to cancer (70).

The active form of the STAT3 transcription factor, called phosphorylated-STAT-3 (p-STAT3) (71), is found in several types of cancers including UCC, and it induces differentiation and maturation of Th17 cells, activating the production of proinflammatory cytokines such as IL-17, IL-6, IL-22, and IL-23 (72). IL-17 promotes positive feedback of Stat3, which induces the IL-17 expression even more, in turn inducing production of the vascular VEGF, prostaglandin E2 (PGE2) and nitric oxide, which then promotes angiogenesis resulting in the formation of new blood vessels and tumor growth (57). Furthermore, IL-17 favors accumulation of neutrophils and increases the resistance of tumor cells to apoptosis. Thus, IL-17 appears to promote a mechanism of carcinogenesis by activating the Stat3 signaling pathway, which triggers the proliferation, migration, and survival of tumor cells by inducing apoptosis resistance and angiogenesis, facilitating the growth and progression of tumors (73).

It has been reported that HPV infection induces constitutive Stat 3 activity and a high level of IL-17 expression, and that the joint action of these two factors may create a pro-inflammatory response in the colorectal epithelium, which in turn may promote carcinogenesis and possibly facilitate the progression of colorectal cancer (74). As HR-HPV infection is the necessary cause of UCC, it is possible that a similar mechanism may contribute to development of the disease. Moreover, studies in humans and animals have shown a positive correlation between increased expression levels of IL-17 in the mucosa of the uterine cervix and development of UCC in patients infected with HPV 16 and 18 (the major oncogenic types of HPV) in relation to other genotypes of the virus $(70,75)$.

In UCC, IL-17 appears to be predominantly produced by innate myeloid cells such as neutrophils which promote tumor growth and are correlated with poor prognosis, while Th17 cells (also producers of IL-17) are correlated with increased survival of the patients, suggesting that these cells are part of a tumor suppressor immune response. As IL-6 and IL-23 are also correlated with poor prognosis of the disease, it has been proposed that these cytokines may induce IL-17 production by myeloid cells, while Th17 cells somehow counteract this response elicited by IL- 6 and IL-32. These data support the hypothesis that the different types of cells expressing IL-17 perform different roles in the tumor microenvironment and have different effects, as indicated by the correlation between the prevalence of Tregs and the increased survival of tumor cells (26).

The markers CD3E, IL-6, and VEGFA, and a high proportion of IL-6/IL-17 combined with low IL-5 expression were identified as the main factors leading to poor prognosis in
UCC. IL- 6 is produced by infiltrating both tumor cells and immune cells, and directly promotes tumor growth. High levels of IL-17 produced by Th17 cells, and of IL-5 produced by Th 2 cells, have been correlated with a more favorable prognosis, especially when compared to levels of expression of Il-6. On the other hand, high expression of IL-6 and VEGFA, with the latter being an inducer of angiogenesis, were together correlated with a poor prognosis. IL17 secreted by Th17 cells could counteract the tumor-promoter effect of IL6, and even more in combined action with the Th2 response characterized by the production of IL5 $(26,76)$.

\section{Cells producing IL-17}

IL-17A is the characteristic cytokine of a unique subset of CD4+ T cells called Th17 cells (77). However, other cell types including CD8 $+\alpha \beta$, T cells $\gamma \delta$, T cells, LTi cells, neutrophils, eosinophils, basophils, mast cells, epithelial cells, endothelial cells and neurons can also produce IL-17A (78-80). Moreover, ovarian tumor cells, tumor-derived fibroblasts and APCs may also contribute to the production of IL-17 by secreting cytokines such as IL-1 $\beta$, IL- 6 , TNF- $\alpha$ and TGF- $\beta$, which create a favorable environment for the differentiation and expansion of IL-17 producing cells (44). IL-17 binds and signals through IL-17 (IL-17R) receptor complexes composed of IL-17RA transmembrane type 1 and IL-17RC, protein subunits that are widely expressed in epithelial cells, endothelial cells and fibroblasts. IL-17/IL-17R binding results in the secretion of inflammatory mediators, including IL-1, IL-6, IL-8, IL-23, TNF and various chemokines that further stimulate the inflammatory cascade $(77,79)$. Studies have shown that IL-17A represents the prototype member of the IL-17 cytokine family and is mainly produced by Th17 cells. Unlike IL-17A, IL-17B is widely expressed in various tissue types and its biological function is associated with pathologies, particularly to tumors (81).

IL-17A is believed to be an immune mediator that evolutionarily emerged as an innate cytokine and after evolved and developed as an adaptive cytokine, since it is more abundantly expressed by thymus-dependent lymphocytes, including adaptive memory Th 2 cells, Th9 cells, CD8+ $\alpha \beta$ T cells, as well as the innate $\gamma \delta$ T cells, invariant natural killer T (iNKT) cells and lymphoid tissue-inducing (LTi) like cells. However, regardless of their evolutionary past, the importance of IL-17A production by innate cell populations and the role that these cells play in shaping the immune response are becoming clearer $(79,80)$.

The differentiation of virgin T cells into Th17 cells appears to involve TGF- $\beta$, IL-6, IL-1 $\beta$, IL-21, and IL-23 signals. In addition, IL- $1 \alpha$ or IL-1 $\beta$ act in synergy with IL-23 to promote IL-17 secretion from memory T cells. Induction or function of Th17 cells is regulated by cytokines secreted by other $\mathrm{T}$ cell subtypes, including IFN- $\gamma$, IL-4, IL-10 and high concentrations of TGF- $\beta$. The main function of IL-17 secreting $\mathrm{T}$ cells is to mediate inflammation, stimulating the production of inflammatory cytokines such as TNF- $\alpha$, IL-1 $\beta$ and IL-6, and inflammatory chemokines that promote the recruitment of neutrophils and macrophages (82).

It has been shown that activated CD8 $+\mathrm{T}$ cells in the presence of the IL- 6 or IL-21 cytokines plus TGF- $\beta$, analogously to the CD4+ T cells, differentiate into Tc17 
producer cells of IL-17. These cells have suppressed cytotoxic function together with low levels of CTL markers such as: T-box transcription factor eomesodermin, granzyme $\mathrm{B}$ and IFN- $\gamma$. Instead, these cells express hallmark molecules of Th17 programming including ROR $\gamma$ t, ROR $\alpha$, IL-21 and IL-23R. The expression of ROR $\gamma \mathrm{t}$ master regulator type 17 is associated with generation of Tc17, since its overexpression stimulates the production of IL-17 in the presence of IL- 6 or IL-21. Both the positive regulation of the type 17 programming as well suppression of differentiation into CTL are dependent on STAT3 (83).

Differentiated Tc17 cells from naïve CD8+ T cells did not possess cytotoxic molecules and do not show strong cytotoxicity. However, when Tc17 effector cells were cultured in the presence of IL-12, they were converted to IFN- $\gamma$ producing Tc17 cells, which mainly consisted of IL-17/IFN- $\gamma$ (Tc17/IFN- $\gamma$ ). Tc17 cells converted with IL-12 also acquired cytotoxic function in addition to the production capacity of IFN- $\gamma$, in addition to showing strong antitumor activity in both in vitro and in vivo (84). In contrast, in another study involving patients with UCC or CIN a greater proportion of Tc17 cells was found in both peripheral blood and cervical tissues of women with these lesions when compared with healthy women. In addition, the number of Tc17 cells in UCC tissues was significantly higher than in the tissues of CIN. The increase in the number of Tc17 in patients with UCC was related to the status of pelvic lymph node metastases and increased microvessel density. Significant correlations between the infiltration of Tc17 cells and Th17 cells or Foxp3 expressing T cells were observed in UCC and CIN tissues. This indicates that the infiltration of Tc17 cells into the UCC is associated with tumor progression accompanied by increased cell infiltration of Th17 and of Tregs, and further promoted tumor vasculogenesis (85).

\section{Cells expressing receptors for the IL-17 family}

There is a wide variety of cells expressing receptors for the cytokine IL-17 family, including T helper type 2, T helper type 9, basophils, fibroblasts, adipose cells, epithelial cells, endothelial cells and chondrocytes (80). The receptors of IL-17 cytokine are mediators of the biological functions of the IL-17 cytokine family composed of six members ranging from IL-17A to IL-17F to pro-inflammatory inducing programs (86), in addition to a heterodimeric species consisting of disulfide-linked IL-17A and IL-17F $(87,88)$. These cytokines signal through a heterodimeric receptor complex consisting of the IL-17RA and IL-17RC chains, which is detected in various cell types $(86,89)$. Although these dimers stimulate many overlapping signaling pathways, the degree of induction varies among species with the IL-17A homodimer eliciting more robust responses than the heterodimer or the IL-17F homodimer (87).

The cytokine receptor family IL-17 is currently constituted by five members (IL-17RA, IL-17RB, IL-17RC, IL-17RD and IL-17RE) which share sequence homology and which interact with six ligands (from IL-17A to IL-17F). All members of this family have a fibronectin III-like domain in their extracellular part and an SEF/IL-17R domain (SEFIR) in their intracellular portion (89). The IL-17RA receptor identified there is often the IL-17 receptor. However, current evidence indicates that IL-17RA is probably a common receptor used by all members of the IL-17 family. On the other hand, the other receptors such as IL-17RB, IL-17RC and IL-17RE were identified as being specific for IL-17E, IL-17A, IL-17F and IL-17C, respectively. Also IL-17RD, originally identified as a negative regulator in fibroblast growth factor signaling, has recently been identified as a negative regulator of the IL-17A signaling $(90,91)$. Cytokines IL-17A and IL-17F were believed to be predominantly secreted by Th17 cells, have been shown to signal through a heteromeric receptor complex. This complex consists of IL-17RA and IL-17RC, which are unique transmembrane proteins ubiquitously expressed in various cell types including epithelial cells, fibroblasts and astrocytes (92). Studies have shown that IL-17A and IL-17F are capable of inducing expression of proinflammatory genes, alone or in synergy with TNF $\alpha$, IL-6, G-CSF, IL-1 $\beta$, CXCL1, CCL20 and matrix metalloproteases (93), promoting the activation of NF- $\kappa B$, MAPK and C/EBP cascades (94). In addition, other studies have shown that the cytokine IL-17 also activates the cell signaling pathways Jak-Stat and Jak-PI3K $(95,96)$. It has also been shown that in addition to altering gene expression, stimulation by IL-17 can stabilize mRNAs by promoting the splicing factor disengagement of the mRNA, preventing its degradation $(97,98)$.

It has been demonstrated that the expression levels of IL-17RB receptor of IL-17 are increased in gastric cancer tissues and that IL-17B/IL-17RB signaling plays a critical role in the progression of this type of tumor. It has also been found that this signaling is associated with poor prognosis in patients with breast cancer. In addition, overexpression of IL-17RB was associated with increased malignancy, metastatic development and reduced survival in patients with pancreatic cancer. It has been also observed that the signal triggered by the interaction of IL-17B with its receptor IL-17RB positively regulates Mesenchymal stem cells (MSCs) through the activation of the AKT/ $\beta$-catenin pathway in gastric cancer. This suggests that IL-17B increases the progression of gastric cancer by the activation of MSCs (81).

\section{Role of IL-17 in UCC}

Potential tumorigenic effect. IL-17 is an inflammatory cytokine with several functions contributing to host defenses, but also participating in the pathology of autoimmune diseases, chronic inflammatory diseases and cancer (70). Reports of abnormally high levels of IL-17 in a large group of malignant tumors in humans suggest the involvement of this cytokine in the tumorigenesis process, according to the currently obtained evidence (99). One of the first studies to produce evidence of the role of IL-17 as a tumorigenic factor in UCC was obtained by Tartour et al (100), in which it was observed that cell lines derived from the tumor cultured with IL-17 showed increased levels of IL-6 and IL-8 expression, two inflammatory cytokines that are usually upregulated in cancer, although no direct effect on cell proliferation was observed.

In a study conducted by Feng et al (101), evidence was found that elevated levels of IL-17A can be used as a marker of prognosis in patients with UCC. This family of cytokines is associated with increased ability to promote migration and invasion of tumor cells by increasing the expression and activity of the MMP2 and MMP9 enzymes in virtue of its 
capacity to downregulate expression of the inhibitors of these enzymes (TIMP-1 and TIMP-2) of the signaling pathway p38/NF- $x$ B (101). In addition, higher concentrations of IL-17 were more frequent in the fresh homogenate of tumor tissue obtained from women with UCC infected with HPV16 or 18 when compared to women infected with other HPV genotypes. On the other hand, higher levels of macrophage and granule colony stimulating factor IL-10 and IL-15 were found in tumors obtained from women infected with different genotypes of HPV16 and 18 (75).

It was shown that the stroma cells of UCC predominantly express CCL20, and that this molecule is correlated with the infiltration of CD4+ cells producing IL-17 in the tumor. In addition, cells of the UCC seem to be able to emit signals that stimulate fibroblasts to produce high levels of CCL20 and attract CD4+ cells producing IL-17 expressing CCR6. It was also found that IL- 6 produced by the tumor cells constitutes an important mediator of paracrine induction of CCL20, activating the transcription of the mRNA to this protein in the fibroblast. Thus, the cervical neoplastic cells modulate the tumor microenvironment by instructing fibroblasts to support Th17 cell infiltration by IL-6 induction in a paracrine manner (102).

In patients with UCC, the accumulation of Th17 cells with activated phenotype and with a marked increase in the expression of receptor CCR6 was found within the tumor. As expected, the levels of CCL20 in the tumor tissue were significantly higher compared to those found in normal tissue, with a strongly positive correlation with the presence of Th17 cells. In addition, in vitro migration assay revealed that CCL20 showed an effective chemotaxis to attract Th17 circulating cells. This suggests that Th17 cells are recruited into the tumor, preferably by means of the CCR6-CCL20 pathway (65).

The potential role of IL-17 in the modulation of the carcinogenic phenotype in the UCC was further reinforced by the finding that IL-17 is produced in vivo by tumor infiltrated CD4+ cells in patients with disease progression (100). In addition, a tendency for gradual increase in the Th17 ratio in the total CD4+ cells with the worsening of the lesion was shown in patients with cervical lesions associated with HPV, along with the same being observed in relation to IL-17 levels in serum and in cervical tissue homogenate supernatant, suggesting that Th17 and IL-17 cells may contribute to the progression of cervical lesions associated with HPV (103).

The possible tumorigenic role of IL-17 has aroused great interest in investigating the polymorphisms in the cytokine gene and its possible association with the increased risk of cancer, including UCC. A case-control study involving 264 patients with UCC and 264 healthy women found a close relationship between the single-nucleotide (SNP) polymorphism common in the IL-17 gene and the disease. The study revealed that the polymorphic genotype AA rs2275913 was strongly associated with increased risk of UCC compared to wild type genotype GG in patients infected with HPV-16 or HPV-18 compared to the control group (99).

This trend was confirmed in four other similar case-control studies, all involving Chinese women. The first study analyzed 352 patients with UCC and 352 healthy women in the control group. It was demonstrated that women with genotype GA and AA for SNP polymorphism rs2275913 in the IL-17A gene presented a higher risk of UCC compared with those with the GG genotype. A significant association was found between the rs2275913 polymorphism and genital infection by HPV 16 or 18 and risk of developing UCC (25). The second study looked at 311 cases of UCC and 463 controls without the disease and found that the frequency of genotype AA for the SNP polymorphism rs2275913 was significantly higher than that found for the GG genotype in the patients with UCC compared to the control group. It was also found that this genetic variation not only increased the susceptibility for disease, but also its severity (104). In the third study which analyzed 216 cases of UCC and 432 controls without the disease, it was demonstrated that patients with the AA genotypic variant of SNP polymorphism rs2275913 showed a significantly higher risk of developing UCC compared to those with wild-type genotype GG (105). The fourth study included 306 cases of UCC and 354 controls free of the disease also showed that women with the AA genotype variant of the polymorphism rs2275913 had a significantly higher risk of developing UCC compared to the wild type genotype GG. In addition, in the latter study it also was found that the A allele of the rs699947 polymorphism of the IL-17 gene was also associated with an increased risk for UCC in patients infected with HPV 16 or 18 (106). On the other hand, in a population-based case-control study involving American women, it was found that the SNP polymorphism rs2275913 of the gene encoding IL-17 was positively associated with UCC for HPV 16 (107).

Cancer cell proliferation. Although it has been shown that IL-17 did not exert any in vitro action on the proliferation of cells derived from cervical cancer, a significant increase in tumor size was observed when these cells were transfected with a cDNA encoding IL-17 and transplanted to nude mice when compared to the parent tumor. It has been found that the action of IL-17 on inducing tumor growth occurred by increasing IL-6 expression which promotes the recruitment of macrophages to the tumor site (100).

The phenotypic analysis of cervical cancer cells by means of immunohistochemistry and immunofluorescence revealed that IL-17 is predominantly expressed by neutrophils (66\%), mast cells (23\%) and innate lymphoid cells (8\%), and to a lesser extent only $4 \%$ by Th17 cells. A similar distribution was also observed in the tumor epithelium. A number above the median total of cells expressing IL-17 in the early stages of the tumor presented an independent factor of poor prognosis, being associated with less survival. A high number of neutrophils and the low number of mast cells also showed a tendency of reduced survival. On the other hand, cells expressing IL-17 and neutrophils were correlated with the absence of vasoinvasion. IL-17 has been shown to enhance cell proliferation or tightness of cervical cancer cell lines, which may be a mechanism for tumorigenesis in the early stage of tumor development. This study suggests that IL-17 mainly expressed by neutrophils promotes tumor growth, being correlated with poor prognosis in the early stage of the disease. Surprisingly, a high number of Th17 cells presented as a factor associated with a favorable prognosis to improve patient survival, suggesting that Th17 cells are part of a tumor suppressor immune response (26). 
Induction of metastasis. Evaluation of IL-17A expression levels and its clinical significance in tissue samples obtained from 50 cases of cervical cancer showed that IL-17A expression did not correlate with patient age, FIGO stage or tumor size, but was significantly correlated with depth of tumor invasion and status of lymphatic metastasis. In addition, IL-17A increased the motility of cancer cells through the upregulation expression of MMP2 and MMP9 and decreased the expression of their natural endogenous inhibitors TIMP-1 and TIMP-2. This suggests that IL-17A acts by increasing tumor cell motility in cervical cancer by being involved in the remodeling of the extracellular matrix (ECM), thus contributing to the invasion and metastasis malignant cells, since the cancer cells need degrading of ECM during the process of metastasis to invade blood or lymph vessels to reach other tissues and organs, and then generate a new tumor (101).

Induction of angiogenesis. Inflammation and angiogenesis are two characteristics of lung adenocarcinoma and are both related to IL-17. Microvessel density was positively associated with the expression of IL-17, IL-6, IL-8 and VEGF, reinforcing the hypothesis that IL-17 contributes to the development of this tumor by inducing angiogenesis through its stimulatory action of IL-6, IL-8 and VEGF (108). Interestingly, UCC bears some resemblance to lung adenocarcinoma, and it was found that IL-17 presented tumorigenic action in UCC-derived cell lines as it induced increased expression of IL-6 and IL-8 (61). Furthermore, VEGF expression levels are also elevated in both precursor and UCC lesions (109), and have been associated with poor survival in patients with this type of tumor (110). Thus, although it has not yet been reported, it is likely that IL-17 may also play a role in the induction of angiogenesis in UCC.

\section{Conclusion}

The role of the Th17 immune response in the development of UCC, as in other types of cancers, has shown to be ambiguous; in some cases protecting against tumors while in others promoting them. Th17 may indirectly exert a protective function against tumors by producing cytokines which promote the recruitment of effector CD8+ T cells for the tumor site, or directly becoming a Th1 cell producing IFN- $\gamma$ that activates CD8+ T cells against tumors. In other conditions, Th17 cells may act in promoting tumor growth by producing cytokines such as IL-6, IL-17, and IL-23, which recruit neutrophils for tumor sites where they produce more IL-17 that leads to chronic inflammation and production of VEGF that induces angiogenesis. This creates a favorable microenvironment for tumors or exerts the suppressive function of immune response against the tumor.

One possible explanation for this ambiguous function of Th17 cells in relation to UCC is the high plasticity presented by these cells, which can convert into non-classical Th1 cells, producers of IL-17 and IFN- $\gamma$, or IL-17 and IL-10, or further into $\mathrm{T}$ regulatory cells, according to the types of cytokines present in the tumor microenvironment. The involvement of Th17 cells in the tumorigenesis process appears to not only be related to their ability to produce and secrete IL-17, but also by the secretion of other cytokines that attract cells to the tumor site. Thus, the contradictory role of Th17 cells may be due to the other cells that also produce IL-17. The high levels of IL-17 expression found in patients with UCC appear to be primarily produced by myeloid cells of the innate immune response, such as neutrophils. This cytokine would be responsible for the promotion of tumor growth, and is related to poor prognosis of the disease.

On the other hand, the IL-17 produced by Th17 cells was correlated with improved prognosis and the highest survival of patients, suggesting that cells with this phenotype are part of the tumor suppressor immune response. It has been proposed that IL-6 and IL-23, whose presence is correlated with poor prognosis in UCC, would be responsible for activating neutrophils to produce IL-17, while the IL-17 produced by Th17 cells antagonizes the response triggered by IL- 6 and IL-23. This strengthens the hypothesis that there are different types of cells producing IL-17, performing different roles and producing different effects in the tumor microenvironment.

\section{Acknowledgements}

Not applicable.

\section{Funding}

Not applicable.

\section{Availability of data and materials}

Not applicable.

\section{Authors' contributions}

JJPA, TAAMF and JVF drafted the manuscript. TAAMF, JMGA, RNOC, DCFL, FLB, VSA and JVF revised the manuscript critically for important intellectual content. FLB, VSA and JVF approved the final version to be published.

\section{Ethics approval and consent to participate}

Not applicable.

\section{Patient consent for publication}

Not applicable.

\section{Competing interests}

The authors declare that they have no competing interests.

\section{References}

1. Catarino R, Petignat P, Dongui G and Vassilakos P: Cervical cancer screening in developing countries at a crossroad: Emerging technologies and policy choices. World J Clin Oncol 6: 281-290, 2015.

2. Torre LA, Bray F, Siegel RL, Ferlay J, Lortet-Tieulent J and Jemal A: Global cancer statistics, 2012. CA Cancer J Clin 65: 87-108, 2015.

3. Ferlay J, Soerjomataram I, Dikshit R, Eser S, Mathers C, Rebelo M, Parkin DM, Forman D and Bray F: Cancer incidence and mortality worldwide: Sources, methods and major patterns in GLOBOCAN 2012. Int J Cancer 136: E359-E386, 2015. 
4. Bosch FX and de Sanjosé S: The epidemiology of human papillomavirus infection and cervical cancer. Dis Markers 23: 213-227, 2007.

5. Lima EG, de Lima DB, Miranda CA, de Sena Pereira VS, de Azevedo JC, de Araújo JM, de Medeiros Fernandes TA, de Azevedo PR and Fernandes JV: Knowledge about HPV and screening of cervical cancer among women from the metropolitan region of Natal, Brazil. ISRN Obstet Gynecol 2013: 930479, 2013

6. Lin Y and Zhan FB: Geographic variations of racial/ethnic disparities in cervical cancer mortality in Texas. South Med J 107: 281-288, 2014.

7. Forman D, de Martel C, Lacey CJ, Soerjomataram I, Lortet-Tieulent J, Bruni L, Vignat J, Ferlay J, Bray F, Plummer M and Franceschi S: Global burden of human papillomavirus and related diseases. Vaccine 30 (Suppl 5): F12-F23, 2012

8. Vaccarella S, Lortet-Tieulent J, Plummer M, Franceschi S and Bray F: Worldwide trends in cervical cancer incidence: Impact of screening against changes in disease risk factors. Eur J Cancer 49: 3262-3273, 2013.

9. Castellsagué X: Natural history and epidemiology of HPV infection and cervical cancer. Gynecol Oncol 110 (3 Suppl 2): S4-S7, 2008.

10. Bodily $\mathbf{J}$ and Laimins LA: Persistent of human papillomavirus infection: Keys to malignant progression. Trends Microbiol 19 $33-39,2011$

11. Muñoz N, Castellsagué X, de González AB and Gissman L: Chapter 1-HPV in the etiology of human cancer. Vaccine 24 (Suppl 3): S3/1-10, 2006.

12. Saavedra KP, Brebi PM and Roa JC: Epigenetic alterations in preneoplastic and neoplastic lesions of the cervix. Clin Epigenetics 4: 13, 2012.

13. Daud II, Scott ME, Ma Y, Shiboski S, Farhat S and Moscicki AB Association between toll-like receptor expression and human papillomavirus type 16 persistence. Int J Cancer 128: 879-886, 2011

14. Mora-García ML and Monroy-García A: Immune response in cervical cancer. Strategies for the development of therapeutic vaccines. Rev Med Inst Mex Seguro Soc 53 (Suppl 2): S206-S211, 2015.

15. Stanley MA: Immune responses to human papilloma viruses. Indian J Med Res 130: 266-276, 2009

16. Song D, Li H, Li H and Dai J: Effect of human papillomavirus infection on the immune system and its role in the course of cervical cancer. Oncol Lett 10: 600-606, 2015.

17. Iwasaki A: Antiviral immune responses in the genital tract: Clues for vaccines. Nat Rev Immunol 10: 699-711, 2010.

18. Sasagawa T, Takagi $\mathrm{H}$ and Makinoda S: Immune responses against human papillomavirus (HPV) infection and evasion of host defense in cervical cancer. J Infect Chemother 18: 807-815, 2012.

19. Stanley M: Immunobiology of HPV and HPV vaccines. Gynecol Oncol 109 (Suppl 2): S15-S21, 2008.

20. Blaskewicz CD, Pudney J and Anderson DJ: Structure and function of intercellular junctions in human cervical and vaginal mucosal epithelia. Biol Reprod 85: 97-104, 2011.

21. Hervouet C, Luci C, Rol N, Rousseau D, Kissenpfennig A, Malissen B, Czerkinsky C and Anjuère F: Langerhans cells prime IL-17-producing T cells and dampen genital cytotoxic responses following mucosal immunization. J Immunol 184 4842-4851, 2010

22. Kemp TJ, Hildesheim A, García-Piñeres A, Williams MC Shearer GM, Rodriguez AC, Schiffman M, Burk R, Freer E, Bonilla $\mathrm{J}$, et al: Elevated systemic levels of inflammatory cytokines in older women with persistent cervical human papillomavirus infection. Cancer Epidemiol Biomarkers Prev 19: 1954-1959, 2010

23. Zhang Y, Ma D, Zhang Y, Tian Y, Wang X, Qiao Y and Cui B: The imbalance of Th17/Treg in patients with uterine cervical cancer. Clin Chim Acta 412: 894-900, 2011.

24. Paradkar PH, Joshi JV, Mertia PN, Agashe SV and Vaidya RA Role of cytokines in genesis, progression and prognosis of cervical cancer. Asian Pac J Cancer Prev 15: 3851-3864, 2014.

25. Cong J, Liu R, Wang X, Sheng L, Jiang H, Wang W, Zhang Y, Yang S and Li C: Association between interluekin-17 gene polymorphisms and the risk of cervical cancer in a Chinese population. Int J Clin Exp Pathol 8: 9567-9573, 2015.

26. Punt S, Fleuren GJ, Kritikou E, Lubberts E, Trimbos JB Jordanova ES and Gorter A: Angels and demons: Th17 cells represent a beneficial response, while neutrophil IL-17 is associated with poor prognosis in squamous cervical cancer. Oncoimmunology 4: e984539, 2015.
27. Dong C: Targeting Th17 cells in immune diseases. Cell Res 24 901-903, 2014

28. Schmitt E, Klein M and Bopp T: Th9 cells, new players in adaptive immunity. Trends Immunol 35: 61-68, 2014.

29. Kaplan MH: Th9 cells: Differentiation and disease. Immunol Rev 252: 104-115, 2013.

30. Goldszmid RS, Dzutsev A and Trinchieri G: Host immune response to infection and cancer: Unexpected commonalities. Cell Host Microbe 15: 295-305, 2014.

31. Damsker JM, Hansen AM and Caspi RR: Th1 and Th17 cells: Adversaries and collaborators. Ann N Y Acad Sci 1183: 211-221, 2010.

32. Mosmann TR, Cherwinski H, Bond MW, Giedlin MA and Coffman RL: Two types of murine helper T cell clone. I. Definition according to profiles of lymphokine activities and secreted proteins. J Immunol 136: 2348-2357, 1986.

33. Wilson JN, Boniface K, Chan JR, McKenzie BS, Blumenschein WM, Mattson JD, Basham B, Smith K, Chen T, Morel F, et al: Development, cytokine profile and function of human interleukin 17-producing helper T cells. Nat Immunol 8: 950-957, 2007.

34. Murphy KM and Reiner SL: The lineage decisions of helper T cells. Nat Rev Immunol 2: 933-944, 2002.

35. Gavin MA, Rasmussen JP, Fontenot JD, Vasta V, Manganiello VC, Beavo JA and Rudensky AY: Foxp3-dependent programme of regulatory T-cell differentiation. Nature 445: 771-775, 2007.

36. Josefowicz SZ, Lu LF and Rudensky AY: Regulatory T cells: Mechanisms of differentiation and function. Annu Rev Immunol 30: 531-564, 2012

37. Asadzadeh Z, Mohammadi H, Safarzadeh E, Hemmatzadeh M, Mahdian-Shakib A, Jadidi-Niaragh F, Azizi G and Baradaran B: The paradox of Th17 cell functions in tumor immunity. Cell Immunol 322: 15-25, 2017.

38. Veldhoen M, Uyttenhove C, van Snick J, Helmby $H$, Westendorf A, Buer J, Martin B, Wilhelm C and Stockinger B: Transforming growth factor-beta 'reprograms' the differentiation of T helper 2 cells and promotes an interleukin 9-producing subset. Nat Immunol 9: 1341-1346, 2008.

39. Eyerich S, Eyerich K, Pennino D, Carbone T, Nasorri F, Pallotta S, Cianfarani F, Odorisio T, Traidl-Hoffmann C, Behrendt H, et al: Th22 cells represent a distinct human $\mathrm{T}$ cell subset involved in epidermal immunity and remodeling. J Clin Invest 119: 3573-3585, 2009

40. Maddur MS, Miossec P, Kaveri SV and Bayry J: Th17 cells: Biology, pathogenesis of autoimmune and inflammatory diseases, and therapeutic strategies. Am J Pathol 181: 8-18, 2012.

41. Peters A, Lee Y and Kuchroo VK: The many faces of Th17 cells. Curr Opin Immunol 23: 702-706, 2011.

42. Ziegler SF and Buckner JH: FOXP3 and the regulation of Treg/Th17 differentiation. Microbes Infect 11: 594-598, 2009.

43. van Hamburg JP, Mus AM, de Bruijn MJ, de Vogel L, Boon L, Cornelissen F, Asmawidjaja P, Hendriks RW and Lubberts E: GATA-3 protects against severe joint inflammation and bone erosion and reduces differentiation of Th17 cells during experimental arthritis. Arthritis Rheum 60: 750-759, 2009.

44. Miyahara Y, Odunsi K, Chen W, Peng G, Matsuzaki J and Wang RF: Generation and regulation of human CD4 ${ }^{+}$ IL-17-producing T cells in ovarian cancer. Proc Natl Acad Sci USA 105: 15505-15510, 2008.

45. Nalbant A and Eskier D: Genes associated with T helper 17 cell differentiation and function. Front Biosci (Elite Ed) 8: 427-435, 2016.

46. Zhang S, Takaku M, Zou L, Gu AD, Chou WC, Zhang G, Wu B, Kong Q, Thomas SY, Serody JS, et al: Reversing SKI-SMAD4-mediated suppression is essential for $\mathrm{T}_{\mathrm{H}} 17$ cell differentiation. Nature 551: 105-109, 2017.

47. Kim HS, Jang SW, Lee W, Kim K, Sohn H, Hwang SS and Lee GR: PTEN drives Th17 cell differentiation by preventing IL-2 production. J Exp Med 214: 3381-3398, 2017.

48. Zhao M, Tan Y, Peng Q, Huang C, Guo Y, Liang G, Zhu B, Huang Y, Liu A, Wang Z, et al: IL-6/STAT3 pathway induced deficiency of RFX1 contributes to Th17-dependent autoimmune diseases via epigenetic regulation. Nat Commun 9: 583, 2018.

49. Karczmarczyk A, Karp M and Giannopoulos K: The role of Th17 cells in tumor immunity Znaczenie limfocytów Th17 w odporności przeciwnowotworowej. Acta Haematol Polonica 45: 155-160, 2014.

50. Shabgah AG, Fattahi E and Shahneh FZ: Interleukin-17 in human inflammatory diseases. Postepy Dermatol Alergol 31: 256-261, 2014. 
51. Fu B, Tian $\mathrm{Z}$ and Wei $\mathrm{H}$ : Th17 cells in human recurrent pregnancy loss and pre-eclampsia. Cell Mol Immunol 11: 564-570, 2014.

52. Arnold CE, Gordon P, Barker RN and Wilson HM: The activation status of human macrophages presenting antigen determines the efficiency of Th17 responses. Immunobiology 220: 10-19, 2015.

53. Guéry L and Hugues S: Th17 cell plasticity and functions in cancer immunity. Biomed Res Int 2015: 314620, 2015.

54. Komatsu N, Okamoto K, Sawa S, Nakashima T, Oh-hora M, Kodama T, Tanaka S, Bluestone JA and Takayanagi H: Pathogenic conversion of Foxp3+ T cells into TH17 cells in autoimmune arthritis. Nat Med 20: 62-68, 2014.

55. Gagliani N, Amezcua Vesely MC, Iseppon A, Brockmann L, Xu H, Palm NW, de Zoete MR, Licona-Limón P, Paiva RS, Ching T, et al: Th17 cells transdifferentiate into regulatory T cells during resolution of inflammation. Nature 523: 221-225, 2015.

56. Eyerich S, Eyerich K, Cavani A and Schmidt-Weber C: IL-17 and IL-22: Siblings, not twins. Trends Immunol 31: 354-361, 2010.

57. Ye J,Livergood RS and Peng G: The role and regulation of human Th17 cells in tumor immunity. Am J Pathol 182: 10-20, 2013

58. Gálvez J: Role of Th17 cells in the pathogenesis of human IBD. ISRN Inflamm 2014: 928461, 2014.

59. Annunziato F, Cosmi L, Liotta F, Maggi E and Romagnani S: Human $\mathrm{T}$ helper type 1 dichotomy: Origin, phenotype and biological activities. Immunology 144: 343-351, 2015.

60. Barnes MJ and Powrie F: Regulatory T cells reinforce intestinal homeostasis. Immunity 31: 401-411, 2009.

61. Davidson MG, Alonso MN, Yuan R, Axtell RC, Kenkel JA Suhoski MM, González JC, Steinman L and Engleman EG: Th17 cells induce Th1-polarizing monocyte-derived dendritic cells. J Immunol 191: 1175-1187, 2013.

62. Morrison PJ, Ballantyne SJ and Kullberg MC: Interleukin-23 and T helper 17-type responses in intestinal inflammation: From cytokines to T-cell plasticity. Immunology 133: 397-408, 2011.

63. Wei L, Wang H, Yang F, Ding Q and Zhao J: Interleukin-17 potently increases non-small cell lung cancer growth. Mol Med Rep 13: 1673-1680, 2016.

64. Young MR, Levingston CA and Johnson SD: Treatment to sustain a Th17-type phenotype to prevent skewing toward Treg and to limit premalignant lesion progression to cancer. Int J Cancer 138: 2487-2498, 2016.

65. Yu Q, Lou XM and He Y: Preferential recruitment of Th17 cells to cervical cancer via CCR6-CCL20 pathway. PLoS One 10: e 0120855, 2015

66. Wu MY, Kuo TY and Ho HN: Tumor-infiltrating lymphocytes contain a higher proportion of FOXP3(+) T lymphocytes in cervical cancer. J Formos Med Assoc 110: 580-586, 2011.

67. Hou F, Li Z, Ma D, Zhang W, Zhang Y, Zhang T, Kong B and Cui B: Distribution of Th17 cells and Foxp3-expressing T cells in tumor-infiltrating lymphocytes in patients with uterine cervical cancer. Clin Chim Acta 413: 1848-1854, 2012.

68. Chen Z, Ding J, Pang N, Du R, Meng W, Zhu Y, Zhang Y, Ma C and Ding Y: The Th17/Treg balance and the expression of related cytokines in Uygur cervical cancer patients. Diagn Pathol 8: 61, 2013.

69. Hou F, Ma D and Cui B: Treg cells in different forms of uterine cancer. Clin Chim Acta 415: 337-340, 2013.

70. Gosmann C, Mattarollo SR, Bridge JA, Frazer IH and Blumenthal A: IL-17 suppresses immune effector functions in human papillomavirus-associated epithelial hyperplasia. J Immunol 193: 2248-2257, 2014.

71. Shukla S, Mahata S, Shishodia G, Pandey A, Tyagi A, Vishnoi K, Basir SF, Das BC and Bharti AC: Functional regulatory role of STAT3 in HPV16-mediated cervical carcinogenesis. PLoS One 8 e67849, 2013

72. Backert I, Koralov SB, Wirtz S, Kitowski V, Billmeier U, Martini E, Hofmann K, Hildner K, Wittkopf N, Brecht K, et al: STAT3 activation in Th17 and Th22 cells controls IL-22-mediated epithelial host defense during infectious colitis. J Immunol 193: 3779-3791, 2014.

73. Gagliani N, Hu B, Huber S, Elinav E and Flavell RA: The fire within: Microbes inflame tumors. Cell 157: 776-783, 2014.

74. Li YX, Zhang L, Simayi D, Zhang N, Tao L, Yang L, Zhao J, Chen YZ, Li F and Zhang WJ: Human papillomavirus infection correlates with inflammatory Stat 3 signaling activity and IL-17 level in patients with colorectal cancer. PLoS One 10: e0118391, 2015.

75. Vidal AC, Skaar D, Maguire R, Dodor S, Musselwhite LW, Bartlett JA, Oneko O, Obure J, Mlay P, Murphy SK and Hoyo C: IL-10, IL-15, IL-17, and GMCSF levels in cervical cancer tissue of Tanzanian women infected with HPV16/18 vs. non-HPV16/18 genotypes. Infect Agent Cancer 10: 10, 2015.
76. Liang W and Ferrara N: The complex role of neutrophils in tumor angiogenesis and metastasis. Cancer Immunol Res 4: 83-91, 2016.

77. Gaffen SL: An overview of IL-17 function and signaling. Cytokine 43: 402-407, 2008

78. Bettelli E, Korn T, Oukka M and Kuchroo VK: Induction and effector functions of T(H)17 cells. Nature 453: 1051-1057, 2008.

79. Cua DJ and Tato CM: Innate IL-17-producin cells: The sentinels of the immune system. Nat Rev Immunol 10: 479-489, 2010.

80. Pappu R, Ramirez-Carrozzi V and Sambandam A: The interleukin-17 cytokine family: Critical players in host defence and inflammatory diseases. Immunology 134: 8-16, 2011.

81. Bie Q, Jin C, Zhang B and Dong H: IL-17B: A new area of study in the IL-17 family. Mol Immunol 90: 50-56, 2017.

82. Mills KH: Induction, function and regulation of IL-17-producing T cells. Eur J Immunol 38: 2636-2649, 2008.

83. Huber M, Heink S, Grothe H, Guralnik A, Reinhard K, Elflein K, Hünig T, Mittrücker HW, Brüstle A, Kamradt T and Lohoff M: A Th17-like developmental process leads to CD8(+) Tc17 cells with reduced cytotoxic activity. Eur J Immunol 39: 1716-1725, 2009.

84. Tajima M, Wakita D, Satoh T, Kitamura $\mathrm{H}$ and Nishimura T: IL-17/IFN- $\gamma$ double producing CD8+ T (Tc17/IFN- $\gamma)$ cells: A novel cytotoxic T-cell subset converted from Tc17 cells by IL-12. Int Immunol 23: 751-759, 2011

85. Zhang Y, Hou F, Liu X, Ma D, Zhang Y, Kong B and Cui B: Tc17 cells in patients with uterine cervical cancer. PLoS One 9: e86812, 2014.

86. Hu Y, Shen F, Crellin NK and Ouyang W: The IL-17 pathway as a major therapeutic target in autoimmune diseases. Ann N Y Acad Sci 1217: 60-76, 2011 .

87. Liang SC, Long AJ, Bennett F, Whitters MJ, Karim R, Collins M, Goldman SJ, Dunussi-Joannopoulos K, Williams CM, Wright JF and Fouser LA: An IL-17F/A heterodimer protein is produced by mouse Th17 cells and induces airway neutrophil recruitment. J Immunol 179: 7791-7799, 2007.

88. Wright JF, Guo Y, Quazi A, Luxenberg DP, Bennett F, Ross JF, Qiu Y, Whitters MJ, Tomkinson KN, Dunussi-Joannopoulos K, et al: Identification of an interleukin 17F/17A heterodimer in activated human CD4+ T cells. J Biol Chem 282: 13447-13455, 2007.

89. Gaffen SL: Structure and signalling in the IL-17 receptor family. Nat Rev Immunol 9: 556-567, 2009.

90. Ron D, Fuchs Y and Chorev DS: Know thy Sef: A novel class of feedback antagonists of receptor tyrosine kinase signaling. Int J Biochem Cell Biol 40: 2040-2052, 2008.

91. Mellett M, Atzei P, Horgan A, Hams E, Floss T, Wurst W, Fallon PG and Moynagh PN: Orphan receptor IL-17RD tunes IL-17A signalling and is required for neutrophilia. Nat Commun 3: 1119, 2012.

92. Trajkovic V, Stosic-Grujicic S, Samardzic T, Markovic M, Miljkovic D, Ramic Z and Mostarica Stojkovic M: Interleukin-17 stimulates inducible nitric oxide synthase activation in rodent astrocytes. J Neuroimmunol 119: 183-191, 2001.

93. Ruddy MJ, Wong GC, Liu XK, Yamamoto H, Kasayama S, Kirkwood KL and Gaffen SL: Functional cooperation between interleukin-17 and tumor necrosis factor-alpha is mediated by CCAAT/enhancer-binding protein family members. J Biol Chem 279: 2559-2567, 2004.

94. Zhu S and Qian Y: IL-17/IL-17 receptor system in autoimmune disease: Mechanisms and therapeutic potential. Clin Sci (Lond) 122: 487-511, 2012.

95. Huang F, Kao CY, Wachi S, Thai P, Ryu J and Wu R: Requirement for both JAK-mediated PI3K signaling and ACT1/TRAF6/TAK1-dependent NF-kappaB activation by IL-17A in enhancing cytokine expression in human airway epithelial cells. J Immunol 179: 6504-6513, 2007.

96. Saleh A, Shan L, Halayko AJ, Kung S and Gounni AS: Critical role for STAT3 in IL-17A-mediated CCL11 expression in human airway smooth muscle cells. J Immunol 182: 3357-3365, 2009.

97. Hartupee J, Liu C, Novotny M, Sun D, Li X and Hamilton TA: IL-17 signaling for mRNA stabilization does not require TNF receptor-associated factor 6. J Immunol 182: 1660-1666, 2009.

98. Sun D, Novotny M, Bulek K, Liu C, Li X and Hamilton TA: Treatment with IL-17 prolongs the half-life of chemokine CXCL1 mRNA via the adaptor TRAF5 and the splicing-regulatory factor SF2 (ASF). Nature Immunol 12: 853-860, 2011.

99. Lv Q, Zhu D, Zhang J, Yi Y, Yang S and Zhang W: Association between six genetic variants of IL-17A and IL-17F and cervical cancer risk: A case-control study. Tumour Biol 36: 3979-3984, 2015. 
100. Tartour E, Fossiez F, Joyeux I, Galinha A, Gey A, Claret E, Sastre-Garau X, Couturier J, Mosseri V, Vives V, et al: Interleukin 17, a T-cell-derived cytokine, promotes tumorigenicity of human cervical tumors in nude mice. Cancer Res 59: 3698-3704, 1999.

101. Feng M, Wang Y, Chen K, Bian Z, Jinfang Wu and Gao Q: IL-17A promotes the migration and invasiveness of cervical cancer cells by coordinately activating MMPs expression via the p38/NF- «B signal pathway. PLoS One 9: e108502, 2014.

102. Walch-Rückheim B, Mavrova R, Henning M, Vicinus B, Kim YJ Bohle RM, Juhasz-Böss I, Solomayer EF and Smola S: Stromal fibroblasts induce CCL20 through IL6/C/EBP $\beta$ to support the recruitment of Th17 cells during cervical cancer progression. Cancer Res 75: 5248-5259, 2015.

103. Xue J, Wang Y, Chen C, Zhu X, Zhu H and Hu Y: Effects of Th17 cells and IL-17 in the progression of cervical carcinogenesis with high-risk human papillomavirus infection. Cancer Med 7: 297-306, 2018

104. Quan Y, Zhou B, Wang Y, Duan R, Wang K, Gao Q, Shi S, Song Y, Zhang L and Xi M: Association between IL17 polymorphisms and risk of cervical cancer in Chinese women. Clin Dev Immunol 2012: 258293, 2012.

105. Li L, Tian YL, Lv XM, Yu HF, Xie YY, Wang JD and Shi W: Association analysis of IL-17A and IL-17F polymorphisms in Chinese women with cervical cancer. Genet Mol Res 14 12178-12183, 2015.
106. Sun LX, Wang XB and Huang XJ: Association analysis of rs $2275913 \mathrm{G}>\mathrm{A}$ and $\mathrm{rs} 763780 \mathrm{~T}>\mathrm{C}$ interleukin 17 polymorphisms in Chinese women with cervical cancer. Genet Mol Res 14: 13612-13617, 2015.

107. Hardikar S, Johnson LG, Malkki M, Petersdorf EW, Galloway DA, Schwartz SM and Madeleine MM: A population-based case-control study of genetic variation in cytokine genes associated with risk of cervical and vulvar cancers. Gynecol Oncol 139: 90-96, 2015.

108. Huang Q, Duan L, Qian X, Fan J, Lv Z, Zhang X, Han J, Wu F, Guo M, Hu G, et al: IL-17 promotes angiogenic factors IL-6, IL-8, and Vegf production via Stat1 in lung adenocarcinoma. Sci Rep 6: 36551, 2016

109. Mandic A, Usaj Knezevic S and Kapicl Ivkovic T: Tissue expression of VEGF in cervical intraepithelial neoplasia and cervical cancer. J BUON 19: 958-964, 2014

110. Zhang J, Liu J, Zhu C, He J, Chen J, Liang Y, Yang F, Wu X and Ma X: Prognostic role of vascular endothelial growth factor in cervical cancer: A meta-analysis. Oncotarget 8: 24797-24803, 2017.

This work is licensed under a Creative Commons Attribution-NonCommercial-NoDerivatives 4.0 International (CC BY-NC-ND 4.0) License. 